IZA DP No. 4859

Are Attitudes Towards Economic Risk Heritable? Analyses Using the Australian Twin Study of Gambling

Anh T. Le

Paul W. Miller

Wendy S. Slutske

Nicholas G. Martin

March 2010 


\title{
Are Attitudes Towards Economic Risk Heritable? Analyses Using the Australian Twin Study of Gambling
}

\author{
Anh T. Le \\ Curtin University of Technology \\ and IZA \\ Paul W. Miller \\ Curtin University of Technology \\ and IZA \\ Wendy S. Slutske \\ University of Missouri \\ Nicholas G. Martin \\ Queensland Institute of Medical Research
}

Discussion Paper No. 4859

March 2010

IZA

P.O. Box 7240

53072 Bonn

Germany

Phone: +49-228-3894-0

Fax: +49-228-3894-180

E-mail: iza@iza.org

Any opinions expressed here are those of the author(s) and not those of IZA. Research published in this series may include views on policy, but the institute itself takes no institutional policy positions.

The Institute for the Study of Labor (IZA) in Bonn is a local and virtual international research center and a place of communication between science, politics and business. IZA is an independent nonprofit organization supported by Deutsche Post Foundation. The center is associated with the University of Bonn and offers a stimulating research environment through its international network, workshops and conferences, data service, project support, research visits and doctoral program. IZA engages in (i) original and internationally competitive research in all fields of labor economics, (ii) development of policy concepts, and (iii) dissemination of research results and concepts to the interested public.

IZA Discussion Papers often represent preliminary work and are circulated to encourage discussion. Citation of such a paper should account for its provisional character. A revised version may be available directly from the author. 
IZA Discussion Paper No. 4859

March 2010

\section{ABSTRACT \\ Are Attitudes Towards Economic Risk Heritable? Analyses Using the Australian Twin Study of Gambling ${ }^{*}$}

This study employs multiple regression models based on DeFries and Fulker (1985), and a large sample of twins, to assess heritability in attitudes towards economic risk, and the extent to which this heritability differs between males and females. Consistent with Cesarini, Dawes, Johannesson, Lichtenstein and Wallace (2009), it is found that attitudes towards risk are moderately heritable, with about 20 percent of the variation in these attitudes across individuals being linked to genetic differences. This value is less than one-half the estimates reported by Zyphur, Narayanan, Arvey and Alexander (2009) and Zhong, Chew, Set, Zhang, Xue, Sham, Ebstein and Israel (2009). While females are more risk averse than males, there is no evidence that heritability in attitudes towards risk differs between males and females. Even though heritability is shown to be important to economic risk taking, the analyses suggest that multivariate studies of the determinants of attitudes towards risk which to not take heritability into consideration still provide reliable estimates of the partial effects of other key variables, such as gender and educational attainment.

JEL Classification: G00, J01

Keywords: risk, heritability, gender

Corresponding author:

Paul W. Miller

School of Economics and Finance

Curtin Business School

Curtin University of Technology

GPO Box U1987

Perth WA 6845

Australia

E-mail: Paul.Miller@curtin.edu.au

\footnotetext{
* This work was supported by National Institutes of Health Grant MH66206 (to Wendy Slutske). Miller acknowledges financial assistance from the Australian Research Council.
} 


\section{ARE ATTITUDES TOWARDS ECONOMIC RISK HERITABLE? ANALYSES USING THE AUSTRALIAN TWIN STUDY OF GAMBLING}

\section{INTRODUCTION}

Preferences for risk play a central role in everyday life. They impact decisions in financial (and insurance) markets, labor markets, and consumer markets. In labor markets they can, for example, affect migration decisions, employment negotiations, a person's career choice, and for a given career, the actions they take and hence their success. In financial markets they can affect investment and retirement portfolios, and hence wealth holdings. In consumer markets, they can, among other things, impact takeup of new products, preferences over health treatments, and bargaining over prices.

Reflecting this central role in everyday life, empirical research has examined whether there are systematic differences in attitudes towards risk across groups in the population. For example, Schubert, Brown, Gysler and Brachinger (1999), Powell and Ansic (1997) and Eckel and Grossman (2002), among others, examine whether there are gender differences in risk aversion. This work is based on experimental evidence. Hartog, Ferrer-i-Carbonell and Jonker (2002), Dohmen et al. (2005), and Bonin, Constant, Tatsiramos and Zimmermann (2008) study sources of heterogeneity in the willingness to take risks using survey data. Hartog et al.'s (2002) analysis aimed to quantify the links between risk aversion and a wide range of individual (e.g., educational attainment, gender), family (e.g., father's job level) and work (e.g., self-employment) characteristics, using several data sets and multivariate methods of analysis. The focus of the research by Dohmen et al. (2005) was on the variations in attitudes towards risk according to gender, age, body height and parental education. Bonin et al. (2008) examine native-immigrant 
differences in willingness to take risk in a multivariate analysis that also covered educational attainment, household income, gender, marital status, family structure, body height, age and location.

The experimental-based and the survey-based evidence on attitudes towards risk have both been criticized. The experimental evidence has been criticized mainly on the grounds that the gambling/insurance experiments may not be well-connected to real world situations. ${ }^{1}$ Different findings have been reported from the study of risk behaviour for abstract and contextual decisions. Survey evidence has been criticized largely because the data sets studied do not offer the control for background circumstances that can be achieved in the laboratory. Dohmen et al. (2005), on the basis of analysis of a data set that contained both information collected via general risk attitude questions and information from a standard lottery experiment, however, have argued that survey measures are behaviorally relevant. ${ }^{2}$

Dohmen et al. (2005) canvass avenues for future research, including establishing whether risk attitudes may be partially determined by genetics. This possibility is addressed by Cesarini, Dawes, Johannesson, Lichtenstein and Wallace (2009), Cesarini, Johannesson, Lichtenstein, Sandewall and Wallace (2010), Zyphur, Narayanan, Arvey and Alexander (2009) and Zhong, Chew, Set, Zhang, Xue, Sham, Ebstein and Israel (2009), where samples of twins are studied to provide evidence on the extent to which genetic variation accounts for heterogeneity in preferences for risk. Cesarini et al. (2009) applied behavioral genetics models to both experimentally elicited preferences for risk

\footnotetext{
${ }^{1}$ See Falk and Heckman (2009) for a rebuttal of the main criticisms of the experimental evidence.

${ }^{2}$ See also Ding, Hartog and Sun (2010).
} 
and to responses to questions from a survey. As with the research by Hartog et al. (2002), Dohmen et al. (2005), and Bonin et al. (2008), the survey-based evidence in Cesarini et al. (2009) was "derived from hypothetical questions that have been behaviorally validated” (Cesarini et al., 2009, p.811). ${ }^{3}$ Cesarini et al. (2009) report that preferences for risk taking are broadly heritable, with about 20 percent of the individual variation being linked to genetic differences. Little of the individual variation in preferences for risk could be linked to common environment factors. Cesarini et al. (2010) report that around 25 percent of the individual variation in portfolio risk is due to genetic variation. This research was based on a field experiment in the form of a major pension reform in Sweden. In contrast, Zyphur et al. (2009) report that a much greater share, of between 45 and 63 percent, of the individual variation in attitudes towards risk was heritable. ${ }^{4}$ Similarly, Zhong et al. (2009) report the heritability of economic risk attitudes to be 57 percent.

Research based on twins has been used previously by economists to good effect in the study of both earnings and educational attainment. ${ }^{5}$ In the study of earnings, the

\footnotetext{
${ }^{3}$ Cesarini et al. (2009) reference the work of Dohmen et al. (2005) in support of this statement.

${ }^{4}$ Classical twin studies assign variation in a phenotype, such as attitudes to risk, to either: additive genetic effects (A); dominant genetic effects (D); shared environmental effects (C); or unshared environmental effects (E). Heritability is the ratio of additive and dominant genetic variation to the total variation. With data only on twins, only D or C can be estimated. D is assumed to be present when the within-twin pair correlation on the phenotype for monozygotic twins is more than twice that for dizygotic twins. Cesarini et al. (2009) estimate an ACE model, as their testing for dominant genetic effects did not yield support for the alternative ADE model. In contrast, Zyphur et al. (2009) report evidence in favor of dominant genetic effects, and hence prefer the ADE model, although they also present results from an AE model (they assumed $\mathrm{C}=0$ to nest this in their ADE model). Their estimate of heritability of 0.45 is from the $\mathrm{AE}$ model, and the estimate of heritability of 0.63 is from the ADE model. The difference between the correlations in the data for monozygotic and dizygotic twins used in the current study is similar to the case in Cesarini et al. (2009), in that the hypothesis that the correlations for dizygotic twins are at least one-half those for monozygotic twins cannot be rejected..

${ }^{5}$ Other applications include to the analysis of health outcomes—see Amin, Behrman and Spector (2009).
} 
framework has been used to address the issue of genetic influences on earnings as well as the bias in the conventional estimate of the return to schooling. Due in large part to Ashenfelter and Krueger (1994), this approach has stimulated considerable interest and has now been applied to data from the US (Ashenfelter and Rouse, 1996), Australia (Miller, Mulvey and Martin, 1995, 2006), the UK (Bonjour, Cherkas, Haskel, Hawkes, and Spector, 2003) and Sweden (Isacsson, 2003). This replication across countries has generated additional confidence in the findings.

The aim of the current study is to provide further evidence on the genetic variation in preferences for risk, using a larger and arguably more representative sample than those used by Cesarini et al. (2009), Zyphur et al. (2009) and Zhong et al. (2009). ${ }^{6}$ Cesarini et al. (2009) based their research on a sample of 319 identical twin pairs, and 141 non-identical same-sex twin pairs. Each twin in a pair needed to live in the same city or surrounding area and was required to attend the same experimental session. Zyphur et al.'s (2009) study was based on 111 identical twin pairs and 89 non-identical twin pairs. Zhong et al.'s (2009) research was based on 167 identical twin pairs and 65 non-identical twin pairs, where each twin was required to attend the same experimental session. The current analysis is based on data from The Australian Twin Study of Gambling, which has 1,875 complete twin pairs, comprising 867 pairs of identical twins and 1,008 pairs of non-identical twins (including both same sex and mixed sex pairs); it also includes 1,014 single twins from pairs where only one completed the survey. These twins were registered by their parents with the Australian Twin Registry during 1980-1982. They were born between 1964 and 1971, and were aged between 32 and 43 years (mean 37.7)

\footnotetext{
${ }^{6}$ See Cesarini et al. (2010) for discussion of some of the limitations of study of twins data obtained from experimental sessions.
} 
at the time the surveys were conducted in 2004-2007. They thus cover a narrower age range than Cesarini et al. (2009), where the twins were born between 1959 and 1985, or Zhong et al. (2009) (age range of 15 to 69 years), but a wider age range than that in the Minnesota Parenting Project data used by Zyphur et al. (2009), where the twins were born between 1961 and 1964, with a mean age at the time of the survey of 36.7 years. Unlike Cesarini et al. (2009) and Zhong et al. (2009), however, we do not have access to data from experimental sessions ${ }^{7}$ : our data are from interviews and self-reported questionnaires. While the data set contains a rich set of information on gambling behavior (see Slutske et al., 2009), the focus of the current study is on responses to two general questions. First "On a scale of 1 to 10, with 1 meaning no risk, and 10 meaning extremely high risk, how much risk are you willing to tolerate when deciding how to invest your money?”. Second, “On a scale of 1 to 10 , with 1 meaning not at all conservative, and 10 meaning extremely conservative, how conservative are you in making decisions about how to spend your money?”.

The current study, while taking a behavioral genetics perspective, will be based on models that will be familiar to economists. Specifically, we use multiple regression models based on DeFries and Fulker (1985), which can be estimated using Ordinary Least Squares, and which offer specifications that enable quantification of the genetic and common environment contributions to attitudes towards risk, along with the contributions of the regressors such as gender, age and educational attainment that have been the focus of past research. The issue of whether the genetic and common environment

\footnotetext{
${ }^{7}$ Likewise, Zyphur et al. (2009) base their analysis on three survey questions.
} 
contributions differ between males and females can be readily assessed within this framework.

The structure of this paper is as follows. Section II outlines the behavioral genetics model of DeFries and Fulker (1985). Section III provides a brief overview of the data set. Included in this brief overview is a presentation of the variation in the responses to the two risk questions according to twin type, gender and age. Section IV presents the results of the estimation of the behavioral genetics model that accounts for variation in attitudes towards risk. Section V concludes.

\section{A BEHAVIORAL GENETICS MODEL}

The starting point for the DeFries and Fulker (1985) model (in the context of a study of the determination of risk preferences) is the estimating equation: ${ }^{8}$

$$
\mathrm{Att}_{\mathrm{ij}}=\alpha_{0}+\alpha_{1} \mathrm{Att}_{-\mathrm{ij}}+\alpha_{2} \mathrm{R}_{\mathrm{ij}}+\alpha_{3} \mathrm{Att}_{-\mathrm{ij}} \mathrm{R}_{\mathrm{ij}}+v_{\mathrm{ij}} \quad \mathrm{j}=1, \ldots, \mathrm{n},
$$

where $\operatorname{Att}_{\mathrm{ij}}$ is the attitude towards risk of the $\mathrm{i}^{\text {th }}$ member $(\mathrm{i}=1,2)$ of the $\mathrm{j}^{\text {th }}$ twin pair $(\mathrm{j}=1$, $n)$, Att $-i j$ is the attitude of the respondent's co-twin, $R_{i j}$ is a coefficient of genetic relationship, which is defined using the fractions of gene frequencies derived in simple biometrical models, namely 1 for identical twins (monozygotic or MZ) and 0.5 for nonidentical (dizygotic or DZ) twins, and $v_{\mathrm{ij}}$ is a stochastic disturbance term. Given this definition of $\mathrm{R}_{\mathrm{ij}}, \alpha_{3}$ is, by construction, twice the difference between the identical and non-identical twins in the regression coefficients on the risk attitude variable of the cotwin. That is, $\alpha_{3}=2\left(\alpha_{M Z}-\alpha_{D Z}\right)$, which given the model formulation can also be written

\footnotetext{
${ }^{8}$ For an application of this model to the study of earnings, see Miller, Mulvey and Martin (1996).
} 
as $\alpha_{3}=2\left(\mathrm{r}_{\mathrm{MZ}}-\mathrm{r}_{\mathrm{DZ}}\right){ }^{9}$ Accordingly, $\alpha_{3}$, under the standard assumptions of an additive model, random mating, and non-common environment of a fraternal twin is not correlated with his/her co-twin's genes, provides a direct estimate of heritability $\left(\mathrm{h}^{2}\right)$ of attitudes towards risk. ${ }^{10}$

$\alpha_{1}$ in this model is an estimate of the twin resemblance that is independent of genetic resemblance (as captured by the other model terms). $\alpha_{1}$ therefore provides a direct estimate of common environmental influences $\left(\mathrm{c}^{2}\right)$. It has been shown that $\alpha_{1}$ and $\alpha_{3}$ yield unbiased estimates of $\mathrm{c}^{2}$ and $\mathrm{h}^{2}$, respectively (see Cherny, DeFries and Fulker, 1992). ${ }^{11}$

The regression model does not constrain the estimates of $c^{2}$ and $h^{2}$ to be in the unit interval. Thus, it is possible to find estimates of $c^{2}$ that are negative and of $h^{2}$ that exceed unity. Of particular concern in the current application is the former possibility (which can indicate the presence of genetic non-additivity, including genetic dominance (allelic interaction) or epistasis (gene $\mathrm{x}$ gene interaction)). In most studies of willingness to take risk, the measures of common environmental influences are found to be of minor importance. For example, if direct measures of family background are included in an equation explaining willingness to take risk (e.g., father’s job level in Hartog et al., 2002, parental educational attainment in Dohmen et al., 2005), they are typically found to be

\footnotetext{
${ }^{9}$ See Fulker, Cardon, DeFries, Kimberling, Pennington and Smith (1991, p.114).

${ }^{10}$ In the context of this study, heritability is the proportion of the variance in attitudes towards risk that is due to genetic factors.

${ }^{11}$ Cherny, DeFries and Fulker (1992) show that, for data sets characterized by moderate twin correlations, compared to the multiple regression model of DeFries and Fulker (1985), the power advantage from maximum likelihood estimation of the genetic and environmental parameters from the covariance structure is minimal.
} 
statistically insignificant and, where statistically significant, economically unimportant. Similarly, in the variance components models of Cesarini et al. (2009) and Zhong et al. (2009), the common environment accounts for a minor portion of the variance in willingness to take risks. Cherny, DeFries and Fulker (1992) show, however, that if the estimate of $c^{2}$ is not significant, the corresponding model term can be omitted from the estimating equation, and the estimate of $\mathrm{h}^{2}$ obtained from the parsimonious model will be unbiased. Preliminary estimations with The Australian Twin Study of Gambling generated small, negative values for the $c^{2}$ component of the variance (typically the estimates were around -0.01 to -0.03 , with ' $t$ ' statistics of about 0.3 ). Consequently, the family environment component has been constrained to equal zero in the estimations presented below.

DeFries and Fulker (1985, p.472) note that their regression model can be extended to include other independent variables, such as gender, age and ethnicity. The additional variables considered for inclusion in this analysis are the educational attainment, age, gender, and marital status variables that have been considered in previous research. Thus, the estimating equation used in this research is given by equation (2):

$$
\begin{aligned}
& \ln A t_{i j}=\alpha_{0}+\underbrace{\alpha_{1} \operatorname{lnAtt}_{-i \mathrm{j}}+\alpha_{2} \mathrm{R}_{\mathrm{ij}}+\alpha_{3} \mathrm{Att}_{\mathrm{ij}} \mathrm{R}_{\mathrm{ij}}}_{\text {Behavioral Genetics Part }}+ \\
& \underbrace{\alpha_{4} \text { Female }_{\mathrm{ij}}+\alpha_{5} \text { EDUC }_{\mathrm{ij}}+\alpha_{6} \mathrm{Age}_{\mathrm{ij}}+\alpha_{7} \text { Married }_{\mathrm{ijj}}}_{\text {Economics Part }}+v_{\mathrm{ij}} \\
& j=1, \ldots, n \text {. }
\end{aligned}
$$

There are two distinct parts to equation (2): The first three terms, which are derived from the behavioral genetics literature, and the final four terms, which are standard in studies such as Hartog et al. (2002) and Bonin et al. (2008). This thus illustrates a further advantage of the DeFries and Fulker (1985) model for this work, in 
that it enables an assessment of the contributions of genetic and common environment variation to attitudes towards risk in the context of a linear regression model similar to that used in prior research in this area.

The models outlined in equations (1) and (2) have been extended to capture differential heritability across levels of cognitive ability (Cherny, Cardon, Fulker and DeFries, 1992), differential heritability by age (Wadsworth, Gillis, DeFries and Fulker, 1989) and differential heritability by gender (DeFries, Gillis and Wadsworth, 1993). This is achieved, in the context of a focus on gender, and in relation to equation (1), by adding gender interaction terms as follows (see, for example, Detterman, Thompson and Plomin, 1990, p.373):

$$
\begin{aligned}
& \text { Att }_{i j}=\alpha_{0}+\alpha_{1} \text { Att }_{-i j}+\alpha_{2} R_{i j}+\alpha_{3} \text { Att }_{-i j} R_{i j}+\alpha_{4} \text { Female }_{i j}+ \\
& \alpha_{8} \text { Female }_{i j} \times \text { Att }_{-i j}+\alpha_{9} \text { Female }_{i j} \times R_{i j}+\alpha_{10} \text { Female }_{i j} \times \text { Att }_{-i j} R_{i j}+v_{i j}
\end{aligned} \quad \mathrm{j}=1, \ldots, n .
$$

In this model, $\alpha_{1}$ is an estimate of environmentality $\left(c^{2}\right)$ for males. $\alpha_{8}$ is an estimate of the differential effect of $c^{2}$ for females compared to males. Similarly, $\alpha_{3}$ is an estimate of heritability $\left(\mathrm{h}^{2}\right)$ for males, and $\alpha_{10}$ is an estimate of the differential effect of $\mathrm{h}^{2}$ for females compared to males.

There is one methodological issue that needs to be considered when using the model of DeFries and Fulker (1985). The model was developed for the case where one twin had a deviant score on the variable of interest, thereby providing a natural index for assignment to the status of "twin" and "co-twin". For applications based on unselected samples, like the study of attitudes towards risk, there are a number of approaches that can be taken (see Cherny, Cardon, Fulker and DeFries, 1992). These include random assignment to the status of "twin" and "co-twin", taking an average of the results from 
multiple trials involving random assignment as "twin" and "co-twin”, and a double entry method. Under the double-entry method, each twin's risk attitude index is entered twice, once as "twin" and once as "co-twin", and all estimations are based on this doubleentered data. Studies that have compared findings from the double-entry method to averages obtained from multiple trials involving random assignment of members of twin pairs to twin and co-twin status in single-entry estimations have found that the two approaches yield similar results, and have preferred the simpler double-entry method (see, for example, Cherny, Cardon, Fulker and DeFries, 1992). Hence the double-entry method is used in this study. Following Cherny, DeFries and Fulker (1992), all standard errors are adjusted for the correct degrees of freedom computed on the basis of the true sample size. This adjustment factor is $\sqrt{\mathrm{df} \text { double-entered/df single entered }}$.

\section{THE AUSTRALIAN TWIN STUDY OF GAMBLING}

The starting point for the data collection is the Australian Twin Registry Younger Cohort (see Miller, Mulvey and Martin, 2006). This comprises a volunteer twin panel born between 1964 and 1971. Nearly all these twins were first registered with the panel between 1980 and 1982 by their parents. The twins have been interviewed at various times and for various purposes: the data for the current study come from interviews and questionnaires for a study of gambling conducted over 2004-2007. The data collection

procedure was quite standard, and details are provided in Slutske et al. (2009). The sample size is 4,764 , which gives an overall response rate in the study of 80 percent. There are 3,750 twins from complete twin pairs, and 1,014 from incomplete pairs. Of the complete twin pairs, 867 are identical twins and 1,008 are non-identical twins. Zygosity 
was determined on the basis of self-reports in the first wave of data collection in 19891992. Inconsistent responses from members of a twin pair were resolved by the Australian Twin Registry. In line with assessments of the accuracy of the self-reported measures of zygosity in other data sets of twins, checking of the self-reports against analysis of DNA showed that the self-reports of zygosity had relatively low misclassification rates (see Slutske et al., 2009).

The Australian Twin Registry Younger Cohort has been used extensively in research (see the web site of the Queensland Institute of Medical Research at qimr.edu.au). Examples of economics publications are Miller, Mulvey and Martin (2005)(2006) and Le et al. (2005). The Australian Twin Study of Gambling is described and analyzed in Slutske et al. (2009). It is argued by Slutske et al. (2009, p.70) to “represent a relatively broad cross-section of the Australian general population" of the relevant age group.

As noted in the Introduction, the two key questions in The Australian Twin Study of Gambling that provide the basis for the current paper are: "On a scale of 1 to 10 , with 1 meaning no risk, and 10 meaning extremely high risk, how much risk are you willing to tolerate when deciding how to invest your money?” and “On a scale of 1 to 10, with 1 meaning not at all conservative, and 10 meaning extremely conservative, how conservative are you in making decisions about how to spend your money?”. These questions will be referred to as RISK and CONSERVE in the analyses that follow. ${ }^{12}$

Table 1 presents information on the responses to the RISK question. Higher values on this variable indicate greater aversion to risk. In this presentation the twins are treated

\footnotetext{
12 Dohmen et al. (2005) contains discussion of the advantages and disadvantages of the survey question approach in relation to study of attitudes towards risk.
} 
as if they are a sample of individuals. The first column is for all valid responses $(\mathrm{n}=$ 4,738). These data have two main features. First, there is a high concentration in the fifth response category (moderate risk taking), with 26 percent of respondents giving this answer. Second, there are relatively few respondents giving high values of the risk index: only six percent of respondents give values of 8 or higher. The mean score is 4.39 (standard deviation of 2.09), and the median is in the same category (5) as the mode.

Columns (ii) and (iii) list data on the distribution of responses to the RISK question for identical and non-identical twins, respectively. These follow the same pattern. The proportions in each risk category are not related to twin type according to the Chi-squared test for independence. The mean responses for identical and non-identical twins are virtually identical.

Table 1

Distribution and Mean of Responses to RISK by Twin Type and Gender

\begin{tabular}{|c|c|c|c|c|c|}
\hline \multirow[b]{2}{*}{ RISK } & \multirow[b]{2}{*}{$\begin{array}{l}\text { Total } \\
\text { (i) }\end{array}$} & \multicolumn{2}{|c|}{ Twin Type } & \multicolumn{2}{|c|}{ Gender } \\
\hline & & $\begin{array}{l}\text { Identical } \\
\text { (ii) }\end{array}$ & $\begin{array}{l}\text { Non-Identical } \\
\text { (iii) }\end{array}$ & $\begin{array}{l}\text { Males } \\
\text { (iv) }\end{array}$ & $\begin{array}{c}\text { Females } \\
(\mathrm{v})\end{array}$ \\
\hline 1 & 11.80 & 11.78 & 11.81 & 8.64 & 14.15 \\
\hline 2 & 8.44 & 8.43 & 8.45 & 6.57 & 9.84 \\
\hline 3 & 15.53 & 16.26 & 14.99 & 13.78 & 16.84 \\
\hline 4 & 10.85 & 10.45 & 11.15 & 10.47 & 11.13 \\
\hline 5 & 25.96 & 24.54 & 27.02 & 25.78 & 26.10 \\
\hline 6 & 11.10 & 11.88 & 10.52 & 12.64 & 9.95 \\
\hline 7 & 10.28 & 10.69 & 9.97 & 14.32 & 7.26 \\
\hline 8 & 3.90 & 3.75 & 4.02 & 5.48 & 2.73 \\
\hline 9 & 0.40 & 0.39 & 0.41 & 0.35 & 0.44 \\
\hline 10 & 1.73 & 1.82 & 1.66 & 1.98 & 1.55 \\
\hline Total & 100.00 & 100.00 & 100.00 & 100.00 & 100.00 \\
\hline Sample Size & 4,738 & 2,029 & 2,709 & 2,025 & 2,713 \\
\hline \multirow{2}{*}{\multicolumn{2}{|c|}{$\begin{array}{l}\text { Test for independ. of } \\
\text { frequencies }\end{array}$}} & & & & \\
\hline & & \multicolumn{2}{|c|}{7.42} & \multicolumn{2}{|c|}{$\underbrace{}_{139.91 * * *}$} \\
\hline \multirow{2}{*}{$\begin{array}{l}\text { Mean Score } \\
\text { ' } t \text { ' for difference in } \\
\text { means }\end{array}$} & 4.39 & 4.40 & 4.39 & 4.77 & 4.11 \\
\hline & & \multicolumn{2}{|c|}{0.18} & \multicolumn{2}{|c|}{$10.79 * * *$} \\
\hline
\end{tabular}

Note: $* * *=$ significant at the 1 per cent level. 
Columns (iv) and (v) list data for males and females, respectively. In this instance the main picture that emerges is that the responses for females are systematically skewed towards the lower risk categories. Thus, the distribution across risk categories are statistically different ( $\chi^{2}$ test of independence yields a test statistic of 139.91), and the mean for males (4.77) is significantly higher than that for females (4.11). Moreover, the median category for females (4) is lower than that for males (5).

Data on the distribution and means of responses to the CONSERVE question are presented in Table 2. For this question, a lower value indicates lesser aversion to risk, and a higher value a more conservative approach. Again, this presentation treats the sample of twins as one of individuals. The first column is for all the sample. Here, the mean of the CONSERVE index is 6.13 (standard deviation is 2.19). The modal category is 5, and the median category is 6 . There are relatively fewer people in the more risk averse tail for the CONSERVE question, and relatively more in the less risk averse tail for this question, than there is for the RISK question. However, other than for these observations there are not great differences. If we were to reverse the order of the coding (so that $10=$ 1 and $1=10$ ) of the CONSERVE index, the mean would be 4.87. In comparison the mean of RISK was 4.39. This suggests that respondents appear to interpret "investment" and "spending" to mean the same, or very similar, thing. Thus one should be able to use the data from the CONSERVE question (focused on spending) to test the robustness of findings based on the data from the RISK question (focused on investment). However, the correlation between RISK and (the re-scaled) CONSERVE is only 0.233 . We return to this issue below. 
This similarity between the two measures carries over to the comparison of the responses to the CONSERVE question on the basis of zygosity and gender. Hence, the distribution of the responses for identical and non-identical twins to CONSERVE do not differ statistically. The responses for females are more skewed towards risk aversion than is the case of males, and the difference in the distributions is statistically significant ( $\chi^{2}$ test of independence yields a test statistic of 101.37).

\section{Table 2}

\section{Distribution and Mean of Responses to CONSERVE by Twin Type and Gender}

\begin{tabular}{|c|c|c|c|c|c|}
\hline \multirow[b]{2}{*}{ CONSERVE } & \multirow[b]{2}{*}{$\begin{array}{l}\text { Total } \\
\text { (i) }\end{array}$} & \multicolumn{2}{|c|}{ Twin Type } & \multicolumn{2}{|c|}{ Gender } \\
\hline & & $\begin{array}{l}\text { Identical } \\
\text { (ii) }\end{array}$ & $\begin{array}{c}\text { Non-Identical } \\
\text { (iii) }\end{array}$ & $\begin{array}{l}\text { Males } \\
\text { (iv) }\end{array}$ & $\begin{array}{c}\text { Females } \\
(\mathrm{v})\end{array}$ \\
\hline 1 & 2.57 & 2.81 & 2.40 & 2.62 & 2.54 \\
\hline 2 & 2.47 & 2.56 & 2.40 & 3.01 & 2.06 \\
\hline 3 & 6.56 & 6.46 & 6.64 & 8.35 & 5.23 \\
\hline 4 & 8.27 & 8.38 & 8.19 & 9.98 & 7.00 \\
\hline 5 & 24.80 & 25.09 & 24.58 & 26.77 & 23.33 \\
\hline 6 & 10.76 & 10.99 & 10.59 & 11.65 & 10.10 \\
\hline 7 & 14.99 & 14.93 & 15.02 & 14.72 & 15.19 \\
\hline 8 & 15.72 & 15.13 & 16.17 & 13.33 & 17.51 \\
\hline 9 & 5.36 & 5.42 & 5.32 & 3.65 & 6.63 \\
\hline 10 & 8.48 & 8.23 & 8.67 & 5.93 & 10.39 \\
\hline Total & 100.00 & 100.00 & 100.00 & 100.00 & 100.00 \\
\hline Sample Size & 4,738 & 2,029 & 2,709 & 2,025 & 2,713 \\
\hline \multirow{2}{*}{\multicolumn{2}{|c|}{$\begin{array}{l}\text { Test for independ. of } \\
\text { frequencies }\end{array}$}} & & & & \\
\hline & & \multicolumn{2}{|c|}{2.38} & \multicolumn{2}{|c|}{$101.37 * * *$} \\
\hline \multirow{2}{*}{$\begin{array}{l}\text { Mean Score } \\
\text { 't' for difference in } \\
\text { means }\end{array}$} & 6.13 & 6.09 & 6.16 & 5.79 & 6.38 \\
\hline & & \multicolumn{2}{|c|}{1.03} & \multicolumn{2}{|c|}{$9.16 * * *$} \\
\hline
\end{tabular}

Note: ${ }^{* * *}=$ significant at the 1 per cent level.

The similarity of identical and non-identical twins on the attitudes to risk (as measured by both RISK and CONSERVE) follows the evidence in Cesarini et al. (2009, Table 1). The gender difference is in line with the survey-based evidence (see Dohmen et al., 2005). Survey-based evidence also suggests that willingness to take risks is 
negatively related to age (see Dohmen et al., 2005). In the current sample, the respondents were born between 1964 and 1971. In principle, this gives a seven-year age range. However, as the interviews spanned 2004-2007, twins can differ in age at interview by 11 years. Investigation of the univariate relationship between attitudes to risk and age showed that there was a weak, negative relationship. However, this was not statistically significant.

The RISK and CONSERVE variables have the expected relationship with selfreports of decision-making under uncertainty in the survey. Hence, for example, twins were asked "If you had sufficient funds, would you prefer to keep your money in the bank or invest it?”. The mean of RISK for twins who reported “Bank” was 3.19 (for CONSERVE it was 6.52) whereas the mean of RISK for those stating "Invest” was 4.67 (CONSERVE $=6.03)$. Both differences are statistically significant. Similarly, a regression of the largest amount the twin had ever gambled in a single bet on, alternatively, RISK and CONSERVE, showed that RISK was significantly and positively related to the amount stated, and CONSERVE was significantly and negatively related to the amount stated. In other words, both RISK and CONSERVE appear to be behaviorally relevant.

The discussion of the data in the Australian Twin Study of Gambling to date has treated the respondents as individuals. Table 3 examines relationships within twin pairs. This presents the correlation between the responses for members of twin pairs by zygosity. Asymptotic standard errors are also reported. The figures in the top panel are for identical twins, and those in the bottom panel are for non-identical twins. 
In each comparison possible in Table 3, the correlation coefficient for identical twins exceeds the correlation coefficient for non-identical twins. ${ }^{13}$ The difference is statistically significant in each case with the RISK measure, but only for the data pooled across males and females for CONSERVE. ${ }^{14}$ Moreover, the correlation coefficients for the CONSERVE variable are less than those for the RISK variable. Inspection of crosstabulations of the risk measures for the twins does not point to any single reason for this, though retest data provide an important insight. One hundred and sixty six subjects were re-tested on the gambling interview, at a mean test-retest interval of 3.5 months. The retest reliability is $\mathrm{r}=0.63$ for RISK, but only $\mathrm{r}=0.26$ for CONSERVE. This suggests that some respondents had difficulty with the CONSERVE question, and given the low reliability for this question, greater emphasis will be placed on the analysis of the RISK data.

\section{Table 3}

\section{Correlation Coefficients for Identical and non-Identical Twins}

\begin{tabular}{|lcc|}
\hline & \multicolumn{2}{c|}{ Measure } \\
\cline { 2 - 3 } Measure & RISK & CONSERVE \\
\hline Identical Twins (all pairs) & $0.241(0.038)$ & $0.156(0.037)$ \\
$\quad$ Females & $0.210(0.048)$ & $0.130(0.049)$ \\
Males & $0.240(0.057)$ & $0.152(0.058)$ \\
& & \\
Non-Identical Twins (all pairs) & $0.105(0.032)$ & $0.074(0.034)$ \\
Females & $0.111(0.058)$ & $0.061(0.056)$ \\
Males & $0.095(0.068)$ & $0.073(0.077)$ \\
Mixed & $0.073(0.048)$ & $0.043(0.051)$ \\
\hline
\end{tabular}

Note: Asymptotic standard errors in parentheses

\footnotetext{
${ }^{13}$ The measures in Table 3 were also computed using a polychoric correlation, and using bootstrapping. There is a minor, though inconsequential, increase in the standard errors under bootstrapping. The polychoric correlation coefficient is slightly larger than the Pearson correlation coefficient in each instance, although the same material conclusions can be drawn regardless of the choice of correlation coefficient.

${ }^{14}$ Statistical significance is assessed using the bootstrapping method proposed by Cesarini et al. (2009, pp.822-823).
} 
The RISK measure is similar to that used by Cesarini et al. (2005). In that study, the mean of the measure of risk was 4.98 for identical twins and 5.25 for non-identical twins, and the difference was at the margin of statistical significance. In the current analysis the mean of RISK is lower, and does not differ by zygosity (Table 1). The correlation for identical twins in Cesarini et al. (2009, Table II) was 0.384, which is higher than that in the current study (Table 3), and the correlation for non-identical twins in Cesarini et al. (2009, Table II), at -0.043, is lower than that in Table $3 .^{15}$

\section{STATISTICAL ANALYSES}

Table 4 lists results from application of the DeFries and Fulker (1985) model to the RISK measure. Table 5 contains the parallel set of results for the CONSERVE measure. The estimates (of heritability and of differential heritability) that are of primary interest are in bold. Prior to discussing these, however, brief comment on the coefficients of the statistically significant gender and educational attainment variables is provided.

Consistent with the earlier discussion, the results in Tables 4 and 5 show that females have a lower propensity to take on risk, and are more conservative. The female effect in the model for RISK implies that they provide scores on the 10-point RISK scale almost one less than their male counterparts. In the case of the CONSERVE measure, the female coefficient is almost two-thirds of a point. The better educated are more likely to take on risk, and are less likely to be conservative in their decision making. An extra 10

\footnotetext{
${ }^{15}$ Comparison data are not available in Zyphur et al. (2009). Zhong et al. (2009) report the correlation for identical twins for their lottery-based measure of risk attitudes to be 0.57 , and for non-identical twins 0.02 .
} 
years of education is associated with an increase in the RISK score of about one, and is associated with a reduction in the CONSERVE score by about one-half a point.

\section{Table 4}

\section{Estimates of Multiple Regression Model of Heritability of RISK}

\begin{tabular}{|c|c|c|c|c|}
\hline Variable & (i) & (ii) & (iii) & (iv) \\
\hline \multirow[t]{2}{*}{ Constant } & 4.354 & 2.445 & 4.829 & 2.567 \\
\hline & (28.94) & (2.97) & (20.97) & (3.03) \\
\hline Risk $_{-i j}$ & 0.0 & 0.0 & 0.0 & 0.0 \\
\hline \multirow[t]{2}{*}{$\mathrm{R}_{\mathrm{j}}$} & -0.965 & -0.793 & -1.074 & -0.955 \\
\hline & (3.95) & (3.27) & $(2.61)$ & $(2.35)$ \\
\hline \multirow{2}{*}{$\mathrm{R}_{\mathrm{j}} \times \mathrm{Risk}_{\mathrm{ij}}$} & 0.234 & 0.192 & 0.224 & 0.196 \\
\hline & (7.00) & (5.79) & (4.09) & (3.64) \\
\hline \multirow[t]{2}{*}{ Gender $_{\mathrm{ij}}$} & (a) & -0.646 & -0.838 & -0.825 \\
\hline & & (6.69) & $(2.78)$ & $(2.77)$ \\
\hline \multirow[t]{2}{*}{ Gender $_{i j} \times R_{j}$} & (a) & (a) & 0.357 & 0.260 \\
\hline & & & $(0.70)$ & $(0.51)$ \\
\hline \multirow{4}{*}{$\begin{array}{l}\text { Gender }_{i j} \times R_{j} \times \\
\text { Risk }_{\text {ij }} \\
\text { Age }_{i j}\end{array}$} & (a) & (a) & -0.014 & -0.003 \\
\hline & & & $(0.21)$ & $(0.05)$ \\
\hline & (a) & 0.027 & (a) & 0.027 \\
\hline & & $(1.31)$ & & (1.29) \\
\hline \multirow[t]{2}{*}{ Education $_{\mathrm{ij}}$} & (a) & 0.097 & (a) & 0.097 \\
\hline & & (5.93) & & $(5.92)$ \\
\hline \multirow[t]{2}{*}{ Married $_{i j}$} & (a) & -0.037 & (a) & -0.037 \\
\hline & & $(0.36)$ & & $(0.37)$ \\
\hline Adjusted $\mathrm{R}^{2}$ & 0.032 & 0.073 & 0.054 & 0.072 \\
\hline True Sample Size & 1779 & 1779 & 1779 & 1779 \\
\hline
\end{tabular}

Notes: Robust 't' statistics in parentheses, adjusted to degrees of freedom of true sample size; estimations constrain $c^{2}=0 ;(a)=$ variable not entered.

Comparison of the estimates for the effects of being female and educational attainment on attitudes to risk with estimates from models that do not include the information on twin type and the co-twins' attitudes towards risk indicates that the control for heritability does not greatly affect these other estimates. For example, the estimate for females corresponding to that in column (ii) of Table 4 is -0.714 , and that for educational attainment is 0.109. In other words, studies such as Hartog et al. (2002) and Dohmen et al. (2005), which do not control for heritability, still provide very reliable 
indications of the importance to willingness to take risk of these variables. As most survey-based studies will not permit a control for heritability, this is an important result.

Turning to the estimate of heritability, it is seen that this is 0.23 in the basic model of DeFries and Fulker (1985) in the case of risk (column (i) of Table 4). When additional controls for personal characteristics are added to the model (column (ii)), the estimate drops to 0.19 , and this is largely due to the inclusion of the variable for educational attainment. The estimates presented in columns (iii) and (iv) of Table 4 indicate there is no evidence that heritability of attitudes towards risk differ between males and females. Exactly the same finding emerges from analysis of heritability separately for males and females. The same findings also arises in models where the constraint that $c^{2}=0$ is not imposed.

In the case of the CONSERVE index (Table 5), the estimate of heritability is a little lower than in the case of RISK, being 0.154 in the simple model of DeFries and Fulker (1985), and 0.134 in the extended model that includes the controls for age, educational attainment, marital status and gender (columns (i) and (ii), respectively in Table 5). Again this slight reduction following the introduction of these statistical controls is linked to the inclusion of the variable for educational attainment. The lower estimate of heritability using CONSERVE is likely to be a result of the lower reliability of this measure. The results presented in columns (iii) and (iv) in Table 5 reveal there is no evidence that heritability of the CONSERVE measure differs between males and females. Again, the same finding of similarity in the estimate of heritability for males and females emerges from analysis of the samples of males and females separately, and in estimations where the constraint that $c^{2}=0$ is not imposed. 


\section{Table 5}

\section{Estimates of Multiple Regression Model of Heritability of CONSERVE}

\begin{tabular}{|c|c|c|c|c|}
\hline Variable & (i) & (ii) & (iii) & (iv) \\
\hline Constant & $\begin{array}{c}6.102 \\
(38.65)\end{array}$ & $\begin{array}{l}7.450 \\
(8.61)\end{array}$ & $\begin{array}{l}5.750 \\
(24.49)\end{array}$ & $\begin{array}{l}7.423 \\
(8.38)\end{array}$ \\
\hline Risk $_{-i j}$ & 0.0 & 0.0 & 0.0 & 0.0 \\
\hline $\mathrm{R}_{\mathrm{j}}$ & $\begin{array}{l}-0.947 \\
(3.30)\end{array}$ & $\begin{array}{l}-0.835 \\
(2.94)\end{array}$ & $\begin{array}{l}-0.838 \\
(2.00)\end{array}$ & $\begin{array}{l}-0.810 \\
(1.95)\end{array}$ \\
\hline $\mathrm{R}_{\mathrm{j}} \times \mathrm{Risk}_{\mathrm{ij}}$ & $\begin{array}{l}0.154 \\
(4.67)\end{array}$ & $\begin{array}{l}0.134 \\
(4.07)\end{array}$ & $\begin{array}{l}0.140 \\
(2.76)\end{array}$ & $\begin{array}{l}0.135 \\
(2.67)\end{array}$ \\
\hline Gender $_{i j}$ & (a) & $\begin{array}{l}0.580 \\
(5.66)\end{array}$ & $\begin{array}{l}0.627 \\
(1.99)\end{array}$ & $\begin{array}{l}0.620 \\
(1.98)\end{array}$ \\
\hline Gender $_{i j} \times R_{j}$ & (a) & (a) & $\begin{array}{l}-0.029 \\
(0.05)\end{array}$ & $\begin{array}{r}-0.045 \\
(0.08)\end{array}$ \\
\hline $\begin{array}{l}\operatorname{Gender}_{i j} \times R_{j} \times \\
\operatorname{Risk}_{-i j}\end{array}$ & (a) & (a) & $\begin{array}{l}-0.007 \\
(0.11)\end{array}$ & $\begin{array}{l}-0.002 \\
(0.03)\end{array}$ \\
\hline Age $_{i j}$ & (a) & $\begin{array}{l}-0.032 \\
(1.47)\end{array}$ & (a) & $\begin{array}{l}-0.032 \\
(1.47)\end{array}$ \\
\hline Education $_{\mathrm{ij}}$ & (a) & $\begin{array}{l}-0.043 \\
(2.43)\end{array}$ & (a) & $\begin{array}{l}-0.043 \\
(2.44)\end{array}$ \\
\hline Married $_{i j}$ & (a) & $\begin{array}{l}0.153 \\
(1.42)\end{array}$ & (a) & $\begin{array}{l}0.153 \\
(1.42)\end{array}$ \\
\hline Adjusted $\mathrm{R}^{2}$ & 0.014 & 0.035 & 0.030 & 0.034 \\
\hline True Sample Size & 1779 & 1779 & 1779 & 1779 \\
\hline
\end{tabular}

Notes: Robust ' $t$ ' statistics in parentheses, adjusted to degrees of freedom of true sample size; estimations constrain $c^{2}=0 ;(a)=$ variable not entered.

The estimates of heritability in the individual variation in attitudes to risk, as captured by the survey measure RISK, at between 19.2 percent and 23.4 percent, are broadly in line with the findings reported in Cesarini et al. (2009) and Cesarini et al. (2010). Cesarini et al. (2009), for example, report (p.811) "Our point estimates from the best-fitting models suggest that approximately twenty percent of individual variation can be explained by genetic differences”. The results in the current study therefore reinforce Cesarini et al.’s (2009) conclusion that preferences for economic risk taking are moderately heritable. This finding contrasts with the results in Zyphur et al. (2009) and 
Zhong et al (2009), where heritability was associated with between 45 and 63 percent of the individual variation in attitudes towards risk.

\section{CONCLUSION}

The study of twins has the potential to inform on the extent to which individual variation in an economic outcome or characteristic can be linked to heritability, shared environmental influences, and individual influences. This approach has previously been applied to the analysis of variations in earnings, educational attainments, and health outcomes. Recently, Cesarini et al. (2009), Cesarini et al. (2010), Zhong et al (2009) and Zyphur et al. (2009) have extended this line of enquiry to attitudes towards risk. The analyses in the current paper provide supportive evidence for the conclusions of Cesarini et al. (2009) and Cesarini et al. (2010), but are at odds with the findings in Zyphur et al. (2009) and Zhong et al (2009). This evidence is derived from an alternative, considerably larger, and arguably more representative data set to those used by Cesarini et al. (2009), Zyphur et al (2009) and Zhong et al. (2009). ${ }^{16}$ It is based on multiple regression models, similar to those used in previous studies (e.g., Hartog et al., 2002), which can be estimated using ordinary least squares and which enable direct estimates of both heritability and common environmental influences.

The results show that, like the study by Cesarini et al. (2009), attitudes towards risk are moderately heritable. About 20 percent of the individual variation in attitudes towards risk can be linked to genetic differences. There is little, if any, difference in

\footnotetext{
${ }^{16}$ Cesarini et al. (2010) have, however, a much larger data set, comprising over 13,000 twin pairs. Martin and Wilson (1982) show that the use of non-random samples of twins can lead to biases in the estimation of heritability. Our further research will investigate this matter with respect to the differences that have emerged in the literature in the study of the heritability of economic risk taking.
} 
heritability between males and females. This finding is robust to estimation on separate samples of males and females, and to estimation with models that constrain the common environment effect to be zero, and which relax this constraint.

The results of the current study also indicate that the findings in Hartog et al. (2002), Dohmen et al. (2005), and Bonin et al. (2008), on the links between attitudes towards risk and individual characteristics, are not be distorted by the absence of controls for genetic influences. Analysis of these large data sets, therefore, remains a valuable source of information on the sources of heterogeneity in the willingness to take risks. 


\section{REFERENCES}

Amin, Vikesh, Behrman, Jere R. and Spector, Tim D., (2009). "Does More Schooling Improve Health Behaviours and Health Oucomes? Evidence from U.K. Twins”, mimeo, Royal Holloway, University of London.

Ashenfelter, Orley and Krueger, Alan, (1994). "Estimates of the Economic Return to Schooling from a New Sample of Twins”, American Economic Review, Vol. 84, No. 5, pp.1157-1173.

Ashenfelter, Orley and Rouse, Cecilia, (1998). "Income, Schooling and Ability: Evidence from a New Sample of Identical Twins”, Quarterly Journal of Economics, Vol. 113, No. 1, pp.253-284.

Bonin, Holger, Constant, Amelie, Tatsiramos, Konstantinos and Zimmermann, Klaus F., (2008). "Native-Migrant Differences in Risk Attitudes", Applied Economic Letters, 99999:1.

Bonjour, Dorothe, Cherkas, Lynn F., Haskel, Jonathan E., Hawkes, Denise D. and Spector, Tim D., (2003). "Returns to Education: Evidence from U.K. Twins", American Economic Review, Vol. 93, No. 5, pp.1799-1812.

Cesarini, David, Dawes, Christopher J., Johannesson, Magnus, Lichtenstein, Paul and Wallace, Björn, (2009). "Genetic Variation in Preferences for Giving and Risk Taking”, The Quarterly Journal of Economics, Vol. 124, No. 2, pp.809-842.

Cesarini, David, Johannesson, Magnus, Lichtenstein, Paul, Sandewall, Örjan and Wallace, Björn, (2010). "Genetic Variation in Financial Decision Making”, Jounral of Finance, forthcoming.

Cherny, S.S., Cardon, L.R., Fulker, D.W. and DeFries, J.C., (1992). 'Differential Heritability Across Levels of Cognitive Ability', Behavior Genetics, Vol. 22, No. 2, pp.153-162.

Cherny, S.S., DeFries, J.C., and Fulker, D.W., (1992). "Multiple Regression Analysis of Twin Data: A Model-Fitting Approach", Behavior Genetics, Vol. 22, No. 4, pp. 489-497.

DeFries, J.C. and Fulker, D.W., (1985). 'Multiple Regression Analysis of Twin Data', Behavior Genetics, Vol. 15, No. 5, pp.467-473.

DeFries, J.C., Gillis, Jacquelyn J. and Wadsworth, Sally J., (1993). "Genes and Gender: A Twin Study of Reading Disability”, pp.187-204 in Albert M. Galaburda (ed.), Dyslexia and Development: Neurobiological Aspects of Extra-Ordinary Brains, Harvard University Press, Cambridge, Massachusetts, USA. 
Detterman, Douglas K., Thompson, Lee Anne, and Plomin, Robert, (1990). "Differences in Heritability Across Groups Differing in Ability”, Behavior Genetics, Vol. 20, No. 3, pp.369-384.

Ding, Xiaohao, Hartog, Joop and Sun, Yuze, (2010). "Can We Measure Individual Risk Attitudes in a Survey?”, IZA Discussion Paper No. 4807, Bonn, Germany.

Dohmen, Thomas, Falk, Armin, Huffman, David, Sunde, Uwe, Schupp, Jürgen and Wagner, Gert G., (2005). "Individual Risk Attitudes: New Evidence from a Large, Representative, Experimentally-Validated Survey”, IZA Discussion Paper No. 1730, Bonn, Germany.

Eckel, Catherine C. and Grossman, Philip J., (2002). "Sex Differences and Statistical Stereotyping in Attitudes Towards Financial Risk", Evolution and Human Behavior, Vol. 23, No. 4, pp.281-295.

Falk, Armin and Heckman, James J., (2009). "Lab Experiments Are a Major Source of Knowledge in the Social Sciences", Institute for the Study of Labor Discussion Paper No. 4540, Bonn, Germany.

Fulker, D.W., Cardon, L.R., DeFries, J.C., Kimberling, W.J., Pennington, B.F., and Smith, S.D., (1991). "Multiple Regression Analysis of Sib-Pair Data on Reading to Detect Quantitative Trait Loci”, Reading and Writing: An Interdisciplinary Journal, Vol. 3, pp. 299-313.

Hartog, J., Ferrer-i-Carbonell, and Jonker, N., (2002). "Linking Measured Risk Aversion to Individual Characteristics”, Kyklos, Vol. 55, pp.3-25.

Isacsson, Gunnar, (2003). "Estimates of the Return to Schooling in Sweden From a Large Sample of Twins”, Labour Economics, Vol. 6, No. 4, pp.471-489.

Le, Anh T., Miller, Paul W., Heath, Andrew C. and Martin, Nick, (2005). "Early Childhood Behaviours, Schooling and Labour Market Outcomes: Estimates from a Sample of Twins”, Economics of Education Review, Vol. 24, No. 1, pp.1-17.

Martin, N.G. and Wilson, S.R., (1982). "Bias in the Estimation of Heritability from Truncated Samples of Twins”, Behavior Genetics, Vol. 12, No. 4, pp.467-472.

Miller, Paul, Mulvey, Charles and Martin, Nick, (1995). "What Do Twins Studies Reveal About the Economic Returns to Education?: A Comparison of Australian and US Findings", American Economic Review, Vol. 85, No. 3, pp.586-599.

Miller, Paul W., Mulvey, Charles and Martin, Nick, (1996). "Multiple Regression Analysis of the Occupational Status of Twins: A Comparison of Economics and Behavioural Genetics Models”, Oxford Bulletin of Economics and Statistics, Vol. 58, No. 2, 1996, pp.227-239. 
Miller, Paul, Mulvey, Charles and Martin, Nick, (2005). "Birth Weight and Schooling and Earnings: Estimates from a Sample of Twins”, Economics Letters, Vol. 86, No. 3, pp.387-392.

Miller, Paul, Mulvey, Charles and Martin, Nick, (2006). "The Return to Schooling: Estimates from a Sample of Young Australian Twins”, Labour Economics, Vol. 13, No. 5, pp.571-587.

Powell, Melanie and Ansic, David, (1997). "Gender Differences in Risk Behaviour in Financial Decision-Making: An Experimental Analysis”, Journal of Economic Psychology, Vol. 18, pp.605-628.

Schubert, Renate, Brown, Martin, Gysler, Mathias and Brachinger, Hans Wolfgang, (1999). "Financial Decision-Making: Are Women Really More Risk Averse", American Economic Review, Papers and Proceedings, Vol. 69, No. 2, pp.381385.

Slutske, Wendy S., Meier, Madeline H., Zhu, Gu, Statham, Dixie J., Blaszczynski, Alex, and Martin, Nicholas G., (2009). "The Australian Twin Study of Gambling (OZGAM): Rationale, Sample Description, Predictors of Participation, and a First Look at Sources of Individual Differences in Gambling Involvement”, Twin Research and Human Genetics, Vol. 12, No. 1, pp.63-78.

Wadsworth, Sally J., Gillis, Jacquelyn J., DeFries, J.C. and Fulker, D.W., (1989). "Differential Genetic Aetiology of Reading Disability as a Function of Age", The Irish Journal of Psychology, Vol. 10, No. 4, pp.509-520.

Zhong, Songfa, Chew, Soo Hong, Set, Eric, Zhang, Junsen, Xue, Hong, Sham, Pak C., Ebstein, Richard P. and Israel, Salomon, (2009). "The Heriotabiltiy of Attitude Toward Economic Risk”, Twin Research and Human Genetics, Vol. 12, No. 1, pp. 103-107.

Zyphur, Michael J., Narayanan, Jayanth, Arvey, Richard D. and Alexander, Gordon J., (2009). "The Genetics of Economic Risk Preferences", Journal of Behavioral Decision Making, Vol 22, pp.367-377. 